\title{
A LUTA HISTÓRICA PELO DIREITO À EDUCAÇÃO NO, DO E PARA O CAMPO: O CONTEXTO DO MUNICÍPIO DE NOVA LARANJEIRAS/PR
}

\author{
THE HISTORICAL FIGHT FOR THE RIGHT TO EDUCATION \\ IN, FROM AND TO THE FIELD: THE MUNICIPALITY OF \\ NOVA LARANJEIRAS/PR CONTEXT
}

Ana Paula Nahirne* Dulce Maria Strieder*

\begin{abstract}
RESUMO:
Muitos são os avanços e os desafios enfrentados pela educação no Brasil, principalmente quando se fala em Educação do Campo. A partir dessa investigacão, foram obtidas respostas para os seguinte questionamento: qual é a visão da comunidade escolar de uma Escola do Campo acerca da concepção e implantação da Educação do Campo em seu contexto local? Uma pesquisa qualitativa com coleta de dados foi realizada em uma Escola do Campo no interior do município de Nova Laranjeiras/PR para o desenvolvimento da investigação, em que participaram tanto a equipe diretiva da escola quanto professores e alunos. Também foi realizada análise documental do Projeto Político Pedagógico (PPP) da escola. Foram utilizados questionários e entrevistas audiogravadas para a coleta dos dados. As categorias foram estabelecidas com base nos dados, de acordo com a análise de Conteúdo proposta por Bardin. Neste âmbito, o objetivo foi analisar o cotidiano desta Escola do Campo e de como ela se insere no contexto local. Constatou-se que os dados mostraram que houve progresso na questão da Educação do Campo, pois a direção da escola e os educadores deram mostras de adaptação às especificidades que essa educação apresenta.
\end{abstract}

Palavras-chave: Educação do campo; Especificidade; Contexto local.

\begin{abstract}
:
Education in Brazil faces many advances and challenges, especially when it comes to Field Education. From this research, we obtained answers to the following question: what is the vision of the school community of a School of the Field about the conception and implementation of Field Education in its local context? Qualitative research with data collection was carried out in a Field School in the countryside of Nova Laranjeiras / PR for the development of the research, in which both the school management team and teachers and students participated. A documentary analysis of the School's Political Educational Project (PPP) was also carried out. Questionnaires and audio-video interviews were used to collect data. The categories were established based on the data collected, according to the Content analysis proposed by Bardin. In this context, the objective was to analyze the daily life of this School of the Field and how it is inserted in the local context. The results of the data analysis showed that there was progress in the field education, since the school management and educators showed adaptations to the specificities that this education presents.
\end{abstract}

Keywords: Field education; Specificity; Local context. 


\section{Introdução}

A Educação do Campo vem ganhando recentemente espaço no cenário das políticas públicas voltadas para a Educação. Acredita-se que, sendo voltada para o campo ou para a cidade, ela deva ser de qualidade, independentemente do lugar, no que se refere à estrutura, formação de professores e currículo. Porém, nem sempre foi dessa maneira, pois basta voltar o olhar ao passado e verificar que nem se falava em Educação do Campo, muito menos se pensava em políticas públicas que atendessem às necessidades das populações que residem nas áreas rurais.

Nesta pesquisa, serão apresentadas algumas compreensões em relação à Educação Rural e à Educação do Campo, no sentido de delimitar seus conceitos e verificar possíveis contradições. Dessa forma, busca-se resposta para o questionamento: qual é a visão da comunidade escolar de uma Escola do Campo acerca da concepção e implantação da Educação do Campo em seu contexto local? Os objetivos foram os de analisar o cotidiano desta Escola do Campo e de como ela se insere no contexto local. Deste modo, a perspectiva foi investigar o ambiente escolar do Colégio Estadual do Campo de Rio da Prata - Ensinos Fundamental e Médio - no cenário da Educação do Campo, localizado no interior do município de Nova Laranjeiras, estado do Paraná.

O colégio escolhido para o desenvolvimento da pesquisa de campo é de grande importância para a autora principal deste artigo, pois foi uma escola construída pelo seu avô Paulo Nairne, juntamente com seu irmão Julio Nairne, na década de 1950, haja vista que foram os primeiros moradores a chegar nesta comunidade. Além disso, como é uma escola que funciona em prédio cedido pela Prefeitura Municipal, possui nível de ensino dos Anos Iniciais ao Ensino Médio, assim, toda a caminhada da autora enquanto aluna destes níveis de ensino foi efetivada nesta escola.

No que se refere à metodologia, além do estudo bibliográfico sobre a Educação de Campo e análise documental do PPP, realizou-se uma pesquisa de campo para que se compreendessem as concepções que a comunidade escolar possui acerca da escola e da formação de educadores. A investigação demandou um contato direto com a direção do colégio, coordenação pedagógica, sete (07) docentes pertencentes ao quadro de educadores de Ciências da Natureza e Matemática e educandos das $1^{\mathrm{a}}, 2^{\mathrm{a}}$ e $3^{\mathrm{a}}$ séries do Ensino Médio.

A coleta de dados caracterizou-se por entrevista audiogravada individual com a direção, equipe pedagógica e educadores de Ciências da Natureza e Matemática, assim como a aplicação de questionários aos educandos do Ensino Médio. Previamente à realização da pesquisa, o projeto foi aprovado pelo Comitê de Ética em Pesquisa com Seres Humanos da Universidade Estadual do Oeste do Paraná (número do comprovante: 080168/2016).

As pesquisas apontam que, em relação à Educação do Campo, os movimentos sociais, as ONGs, os educadores, enfim, a sociedade organizada, têm intensificado os debates junto aos Governos Federal e Estadual, quanto às demandas de construção e implementação de políticas educacionais voltadas para as necessidades dos sujeitos do campo.
No entanto, apesar dos avanços, atualmente, uma das maiores problemáticas da Educação do Campo é justamente a falta de políticas públicas que sustentem o avanço na discussão da proposta de educação básica do campo.

\section{Educação rural e educação do campo: delimitando conceitos e verificando as contradições}

Nas últimas décadas, muito se tem discutido sobre educação no Brasil. É importante reconhecer que houve avanços, mas ainda há muitas dificuldades a serem superadas, para que se tenha uma escola pública de qualidade para todos. E elas ficam ainda mais evidentes nas escolas localizadas na área rural, onde a população ainda sofre com o descaso, quando se trata, mais precisamente, de políticas públicas voltadas à educação.

No século XX, com o início da industrialização, o tipo de mão de obra passou a ser outro, situação que modificou também o papel da escola. O ensino rural, nesse cenário, tinha por objetivo suprir as necessidades econômicas e fomentar o crescimento da monocultura, cujo objetivo era preparar as pessoas para aumentar a produtividade e consequentemente os lucros (CALAZANS, 1981).

A história da educação na área rural teve seus primeiros aparecimentos quando o país ainda era totalmente agrário, e o campo era considerado lugar de atraso. Esses fatos demonstram que a educação voltada para os povos do campo sempre esteve em segundo plano, e só era discutida quando precisava atender às necessidades da sociedade capitalista.

A escola rural envolve dimensões problemáticas bastante extensas,

\begin{abstract}
[...] considerando-se que, historicamente, a educação em si sempre foi negada ao povo brasileiro e, especificamente, ao homem do campo. Vinculada ao sistema produtivo, a escolaridade campesina também serviu de suporte para a estruturação de uma sociedade desigual e de preparo mínimo de mão de obra que atendesse prerrogativas políticoeconômicas (LEITE, 1999, p. 53).
\end{abstract}

$\mathrm{O}$ homem do campo sempre esteve à margem da sociedade, inclusive em relação à educação. Nesse sentido, a Educação Rural surge com o objetivo de fixar o homem no campo, mas, ainda assim, em muitos casos, essa educação esteve voltada para a exploração dos ruralistas, por meio do trabalho manual nos grandes latifúndios em regiões onde estes estavam presentes.

Diante desse cenário, o êxodo rural tornava-se cada vez mais frequente, estendendo a pobreza nas favelas e nos centros urbanos. Nesse período, surgem alguns movimentos de transformação da educação, entre eles o chamado 'ruralismo pedagógico', que defendia a ideia de que a escola rural teria a função de proporcionar o desenvolvimento das populações e a fixação do homem no campo, adaptando a escola às condições desses sujeitos e, consequentemente, mantendo-os em sua região de origem (RIBEIRO, 2012). 
Os desafios encontrados para a efetivação de uma educação que compreenda as especificidades que existem no meio rural são muitos. Todavia, há uma nova proposta de educação que nasce junto com as lutas sociais, que busca melhorias para os povos do campo. Assim, "uma nova concepção vem sendo forjada pelos próprios sujeitos históricos e coletivos do campo que, mobilizados, caminham rumo ao resgate de uma dívida social e histórica: uma educação do/no campo" (PARANÁ, 2009, p. 89).

Arroyo, Caldart e Molina são autores que debatem e discutem uma proposta de Educação do Campo que atenda às especificidades do campo. Para eles,

\begin{abstract}
A Educação do Campo é um conceito cunhado com a preocupação de se delimitar um território teórico. Nosso pensamento é defender o direito que uma população tem de pensar o mundo a partir do lugar onde vive, ou seja, da terra que pisa, melhor ainda a partir de sua realidade. Quando pensamos o mundo a partir de um lugar onde não vivemos, idealizamos um mundo, vivemos um não lugar. Isso acontece com a população do campo quando pensa o mundo $\mathrm{e}$, evidentemente, o seu próprio lugar a partir da cidade. Esse modo de pensar idealizado leva ao estranhamento de si mesmo, o que dificulta muito a construção da identidade, condição fundamental na formação cultural (ARROYO; CALDART; MOLINA, 2009, p. 141-142).
\end{abstract}

Somente do final da década de 1980 e início da década de 1990, iniciou-se um despertar diferenciado, sob o incentivo dos movimentos e organizações voltadas para o campo. É possível identificar que essa nova proposta, segundo Caldart (2012, p.263), "constitui-se como luta social pelo acesso dos trabalhadores do campo à educação (e não a qualquer educação) feita por eles mesmos e não apenas em seu nome". Nesse sentido, a Educação do Campo "não é para nem apenas com, mas sim, dos camponeses, expressão legítima de uma pedagogia do oprimido" (CALDART, 2012, p. 263).

Seguindo esse mesmo raciocínio, o Caderno Temático da Educação do Campo ressalta que

[...] são os povos do campo e toda a sua diversidade, organizados coletivamente, que emergem contrariando sua História de negação, de marginalização, cobrando do Estado uma outra forma de fazer política, e da sociedade em geral, uma nova compreensão sobre seus modos de vida (PARANÁ, 2009, p. 64).

Atualmente, de acordo com Kolling, Nery e Molina (1999, p.26), não é mais corriqueiro usar a expressão "meio rural", mais sim "campo", "com o objetivo de incluir no processo da conferência uma reflexão sobre o sentido atual do trabalho camponês e das lutas sociais e culturais dos grupos que hoje tentam garantir a sobrevivência desse trabalho".

Caldart (2012, p. 264) defende uma educação que crie condições materiais para a vida no campo, buscando a soberania alimentar ${ }^{2}$ por meio de um desenvolvimento sustentável. " $E$ isso se refere tanto ao debate da educação quanto ao contraponto de lógicas de produção da vida, de modo de vida".

A Educação do Campo precisa ter um dos pilares firmado na preocupação com a formação de valores éticos, morais e culturais, bem como com a construção de uma consciência crítica e política. Dessa forma,
[...] a essa concepção de Educação do Campo, confere-se o reconhecimento desses novos sujeitos que vem interagindo com formas de resistência pela sobrevivência no campo, com a luta pela terra, por políticas públicas que deem condições de tirar da terra o sustento de suas famílias, constituindo uma nova forma de produzir cultura, valores, conhecimentos, sujeitos, bem como de compreender o campo para além do aspecto produtivo e econômico. (PARANÁ, 2009, p. 89)

Assim, para se entender a discussão que ocorre em torno das perspectivas e desafios que levaram a uma concepção de educação direcionada para os sujeitos do campo, é necessário compreender suas origens e as contribuições para sua construção.

Kolling, Cerioli e Caldart (2002, p. 19) abordam que a preocupação principal é com a escolarização dos povos do campo, pois compreendem que a educação engloba "os processos sociais de formação das pessoas como sujeitos de seu próprio destino". Logo, "a escola deve ajudar seus educandos a serem sujeitos capazes de refletir sobre o mundo e suas diferenças e lutar para transformá-lo" (PARANÁ, 2009, p. 89). Dessa fala, depreende-se que a escola deve promover uma formação integral e de transformação social, ou seja, deve trabalhar com metodologias que tenham como base o respeito e a valorização dos sujeitos do campo, sua cultura, seu trabalho, sua relação com o meio em que estão inseridos e o seu convívio social. É fundamental que os instrumentos e materiais, como os livros didáticos das escolas do campo, sejam embasados neste contexto.

A Educação do Campo, enquanto política pública, está voltada aos interesses dos sujeitos do campo para construir a relação dialética entre teoria e prática. Logo, de acordo com os conteúdos formais, ela deve proporcionar uma reflexão sobre a realidade em que o indivíduo está inserido, bem como sobre a realidade mais ampla. Assim, contribui-se para instrumentalizar os sujeitos, a fim de que possam intervir significativamente sobre essas realidades. Um dos objetivos da Educação do Campo é "mobilizar o povo que vive no campo, com suas diferentes identidades, e suas organizações para conquista/construção de políticas públicas na área da educação e, prioritariamente, da escolarização em todos os níveis." (KOLLING; CERIOLI; CALDART, 2002, p. 17).

Para que a Educação do Campo seja contemplada nas políticas públicas de maneira ampla, é preciso que o governo atenda às necessidades dos trabalhadores/as do campo. A definição de políticas públicas precisa considerar os aspectos que fortaleçam a formação de educadores/as que atuam nas escolas do campo, bem como a valorização do trabalho e das lutas sociais e culturais do povo camponês. A educação precisa visar o desenvolvimento social, cultural e econômico dos sujeitos que vivem e trabalham no campo.

Em âmbito governamental, diversas ações no Estado no Paraná estão sendo efetivadas e objetivam atender às demandas dos sujeitos do campo. Isto permite refletir que, para que se efetive a proposta de Educação do Campo, faz-se necessário que o Estado, em parceria com o Governo Federal, assuma suas responsabilidades. É preciso que ele se engaje no desenvolvimento de políticas públicas voltadas para a Educação dos povos do 
campo, a fim de que se evidencie certa atenção para com a transformação da sociedade, e ela se torne cada vez mais justa e igualitária.

Nesse sentido, uma Escola do Campo será aquela que, além de trabalhar o conteúdo pedagógico, prepara o educando para que ele possa ampliar sua capacidade reflexiva, desenvolva autonomia crítica e adquira embasamento teórico e, assim, possa intervir na realidade social de sua comunidade e do seu país. Age também sobre as decisões da administração pública na luta por políticas educacionais que atendam toda a população.

\section{Fundamentos teóricos, procedimentos e instrumentos}

O presente trabalho aborda uma pesquisa qualitativa, em que, segundo Flick (2009), consiste na escolha pertinente de métodos e teorias, quando analisa as diferentes perspectivas. Dessa forma, tratou-se inicialmente da realização de um estudo bibliográfico sobre a Educação de Campo.

Salienta-se que as leituras feitas sobre a temática contribuíram significativamente para o trabalho anterior ao da coleta de dados e permaneceram durante todo o trabalho realizado. Nesse sentido, a pesquisa de campo foi um recurso utilizado que possibilitou compreender as informações coletadas a partir da população pesquisada.

Deste modo, a perspectiva é investigar o cotidiano escolar do Colégio Estadual do Campo de Rio da Prata - Ensinos Fundamental e Médio - no cenário da Educação do Campo, localizado a $24 \mathrm{~km}$ da sede do município de Nova Laranjeiras, estado do Paraná.

Dessa forma, foi necessária uma aproximação com a direção e coordenação pedagógica do colégio, bem como sete $(07)$ docentes pertencentes ao quadro de educadores de Ciências da Natureza e Matemática e educandos das $1^{\mathrm{a}}, 2^{\mathrm{a}}$ e $3^{\mathrm{a}}$ séries do Ensino Médio. A coleta de dados caracterizou-se por entrevista audiogravada individual com a direção, equipe pedagógica e educadores de Ciências da Natureza e Matemática, assim como a aplicação de questionários aos educandos do Ensino Médio.

Segundo Triviños (1987), os questionários e entrevistas semiestruturadas têm por finalidade questionamentos básicos apoiados em teorias e hipóteses que se relacionam ao tema da pesquisa.

Por questões éticas, os sujeitos da pesquisa foram protegidos, deste modo, foram apenas identificados por siglas para que a análise dos resultados fosse possível, sendo elas: D (diretora), $\mathrm{P}$ (coordenadora pedagógica), E (educadores) seguida de numeração $(1,2,3, \ldots)$ e $\mathrm{A}$ (alunos), seguidas de numeração $(1,2,3,4, \ldots)$.

A escolha da metodologia de análise baseia-se a partir da Análise de Conteúdo - AC , metodologia já tradicional nas pesquisas educacionais. Após escolhida a Análise de Conteúdo como instrumento norteador na compreensão das informações obtidas, são estruturadas categorias e, segundo Bardin (1977), seguem as seguintes etapas: pré-análise, identificação e organização do material mapeado, codificação e categorização dos trabalhos por agrupamento, interpretação e reflexões.

$\mathrm{Na}$ presente pesquisa, a etapa de pré-análise foi realizada pela leitura das entrevistas realizadas, com o intuito de entender o discurso de cada indivíduo participante da pesquisa. Já na etapa da exploração dos dados coletados, foram extraídas as informações contidas nas entrevistas e nos questionários, recortando informações coletadas, com o objetivo de se classificarem os conteúdos sistematicamente em função das categorias elaboradas.

Finalizadas as etapas, o pesquisador realiza a classificação e a incorporação dos dados da pesquisa e escolhe as categorias teóricas ou empíricas, responsáveis pela particularidade do tema (BARDIN, 1977; MINAYO, 2007). É nesse momento que o pesquisador propõe inferências; procedem-se interpretações relacionadas com a fundamentação teórica previamente elaborada, e, por conseguinte, geram-se novas discussões, atreladas aos dados da pesquisa.

Os dados foram colocados em quatro categorias preestabelecidas, subdivididas em subcategorias que emergiram dos categorizados. Porém, para este trabalho será analisado a categoria Educação do Campo, com as seguintes subcategorias: Implementação da Educação do Campo; Concepção de Educação do Campo e Perspectivas de manutenção de jovens no campo.

\section{Categoria educação do campo}

\subsection{Implementação da Educação do Campo}

No que se refere à categoria da pesquisa, denominada Educação do Campo, considera-se que o recolhimento dos dados ocorreu junto à comunidade escolar, localizada na zona rural do município.

Conforme o PPP da escola, no mês de junho de 2011, através da Secretaria de Estado da Educação, pelo Departamento da Diversidade/Coordenação da Educação Escolar do Campo, e Resolução SEED n ${ }^{\circ}$ 4783/10 da Secretaria da Educação, reconhece-se a Educação do Campo como uma política Pública educacional voltada ao atendimento de ensino das populações rurais nas Escolas do Campo e são instituídas normas e princípios para a implementação da Educação Básica do Campo no Sistema Estadual de Ensino do Paraná, bem como do processo de definição da identidade dessa categoria de Escola.

A solicitação foi atendida pela Resolução $n^{\circ}$ 2849/12 de 15/05/2012, de acordo com a Deliberação da CNE/CEB no 1 de 03/04/2002, da adequação do projeto institucional das escolas do campo às Diretrizes Curriculares Nacionais, para os diversos níveis de ensino. A instituição de ensino passou, a partir desse momento, a denominar-se Colégio Estadual do Campo de Rio da Prata - Ensinos Fundamental e Médio, a qual se caracteriza como Escola do Campo e está se adequando aos princípios da Educação do Campo (PPP, 2015). No entanto, a 
diretora relata que essa mudança de nomenclatura foi alvoroçada. Segundo ela,

[...] essa denominação foi frustrante... porque está localizada no campo mas se nós analisarmos... estamos fazendo um grande esforço para tentar realmente fazer uma Educação do Campo... na prática a gente acaba se decepcionando um pouco pelo fato de não ser tudo aquilo que você está buscando... Então a gente vê que as escolas do campo... estão tendo mas uma nomenclatura e de fato uma efetivação nessa Educação... que deveria ser pensada para o campo não está ocorrendo, nós estamos tentando construir isso... mas está indo a passos muito lentos (D).

A mudança ocorreu devido ao colégio atender somente a educandos oriundos do campo. No entanto, apesar de ter havido a troca na nomenclatura, essa não resultou em mudança significativa nas práticas pedagógicas.

Entende-se que faria maior diferença se novas práticas pedagógicas estivessem acompanhadas da nova nomenclatura e, assim, pudessem melhor expressar os interesses e necessidades dos sujeitos que vivem, trabalham e estudam no campo. Não é meramente a reprodução dos valores do desenvolvimento urbano. O conceito de Educação do Campo fundamenta-se na prática educativa, com o amparo da Lei de Diretrizes e Bases da Educação (LDB), $n^{\circ}$ 9.394/96, que determina, em seu artigo $1^{\circ}$ :

A educação deve abranger os processos formativos que se desenvolvem na vida familiar, na convivência humana, no trabalho, nas instituições de ensino e pesquisa, nos movimentos sociais e organizações da sociedade civil e nas manifestações culturais (BRASIL, 1996, p.1).

Assim, entende-se que a educação está presente em todos os processos formativos ocorridos ao longo da vida dos indivíduos, dentro e fora da escola. Por isso, é fundamental a real implantação de uma educação voltada ao campo, que possa incentivar os educandos e comunidade escolar a pensar de maneira crítica, (porque as pessoas pensam com ou sem escola) almejar e lutar por políticas públicas que efetivamente tragam qualidade de vida ao homem do campo, para que o educando aprenda a produzir seu próprio sustento e seja motivado a permanecer na área rural, ainda que isso o restrinja a este local.

Apesar de a escola estar localizada na zona rural, não apresenta um trabalho totalmente voltado para o campo, mas de acordo com as percepções dos entrevistados, os professores procuram adequar seus planejamentos à realidade em que os educandos estão inseridos. Os relatos condizem com as falas dos entrevistados:

Eu sempre tento relacionar o que consigo... $e$ sempre procuro mostrar para meus alunos que não é porque eles moram no campo com aquela visão de aluno atrasado, atrapalhado, ou que tenha menos oportunidade já não faz mais sentido nessa época e que eles têm tanto quanto ou melhores oportunidade que residem ou que estudam na cidade (E2).

Nesta perspectiva, o planejamento do professor deve conter desde os objetivos do conteúdo a ser trabalhado, sempre levando em consideração o conhecimento empírico trazido pelos educandos, até a aplicação das atividades, tendo em vista que elas devem despertar curiosidade, interesse e motivação aos educandos.

\subsection{Concepção de Educação do Campo}

A Educação do Campo, conforme Resolução $\mathrm{CNE} / \mathrm{CEB} \mathrm{n}^{\circ} 2$, de 28 de abril de 2008, é definida na linguagem oficial, como

Art. $1^{\circ}$ A Educação do Campo compreende a Educação Básica em suas etapas de Educação Infantil, Ensino Fundamental, Ensino Médio e Educação Profissional Técnica de nível médio integrada com o Ensino Médio e destina-se ao atendimento às populações rurais em suas mais variadas formas de produção da vida - agricultores familiares, extrativistas, pescadores artesanais, ribeirinhos, assentados e acampados da Reforma Agrária, quilombolas, caiçaras, indígenas e outros (BRASIL, 2010, p.1).

É possível confrontar esta definição com o que expõem os entrevistados, quando se observa a definição presente na percepção que cada um explicita sobre a terminologia Educação do Campo: "Vejo que é fazer a relação entre o conteúdo científico e a prática do dia-a-dia, conseguir fazer esse elo de ligação pra que eles entendam o porquê de estudar tal conteúdo e onde podem aplicar" (E6). Além disso,

\begin{abstract}
A Educação do Campo deveria ser pensada para alunos do campo, com qualidade... deveria considerar que essas pessoas moram no campo, sobrevivem do campo ou em redor do campo... e... que um dia talvez permaneçam talvez não, então eles têm que ter o conhecimento geral e globalizado... procurar dar aos alunos do campo as mesmas oportunidades das escolas que não são do campo (E1).
\end{abstract}

De um modo geral, vejo que a Educação do Campo é trazer o aluno para a realidade por meios dos conteúdos que ele vê na escola, nos conteúdos que ele vê tentar relacionar com o seu cotidiano. Claro que na cidade a gente trabalha relacionando a sua realidade, mas são questões diferentes, por exemplo, aqui eles veem os aditivos químicos da adubação, fertilização na cidade eu não enfoco isso (E7).

Deveria ser uma educação voltada para os sujeitos do campo, que respeita os sujeitos do campo em seu modo de vida, me sua cultura, seu ritmo, porque são alunos trabalhadores, que trabalham em casa em um período e no outro eles vem pra escola, às vezes cansados. Deveria ter um currículo diferenciado que respeite o filho do trabalhador, enquanto trabalhador. Mas isso nós levamos em conta (P).

Ao meu entender, a Educação do Campo deveria buscar disciplinas mais especificas, que trabalhasse mais com a realidade do campo, que tivesse profissionais realmente capacitados em algumas áreas para estar oferecendo esse trabalho mais a campo pros alunos e eu vejo que isso é umas das dificuldades, porque eu vejo por mim, eu na minha formação de Geografia eu posso até fazer alguns trabalhos de campo com meus alunos, mas a todo o momento, assim como o professor de outras áreas consegue em alguns momentos abranger algo, mas não muito específico (D).

Compreende-se, nessas exposições, que a perspectiva pedagógica da Educação do Campo deve estar ligada a um projeto político e econômico de desenvolvimento local e sustentável, a partir da possibilidade dos interesses dos povos que ali vivem. São estas questões e suas contradições, bem como as práticas organizacionais, os desafios impostos ao debate da Educação do Campo que podem corroborar para sua efetivação dentro da educação pública do Paraná.

As Diretrizes Curriculares da Educação do Campo (CURITIBA, 2006) enfatizam que, por muitos anos, a educação camponesa foi efetivada pautada em 
um currículo extremamente urbano, desconectado da realidade das pessoas que vivem no meio rural e agrário. Diante desse contexto, a Educação Rural contrariava os propósitos da população campesina, que começou a buscar, em meio a outros direitos sociais, o direito a políticas educacionais específicas e diferenciadas para o campo.

$\mathrm{Na}$ educação rural, houve pouca tentativa de adequar a escola às características dos camponeses e dos seus filhos, ou seja, metodologias apropriadas às reais necessidades e interesses dos alunos da zona rural. No estudo, dificilmente havia o objetivo de oferecer uma associação com a realidade desses alunos trabalhadores do campo, considerando que são eles, juntamente com os demais membros da sua família e da comunidade, que garantem o próprio sustento.

O processo de construção da Educação do Campo é uma luta antiga das populações que residem nas comunidades rurais do país e lutam por uma educação de qualidade, baseada nas especificidades do campo. Conforme Ribeiro (2012. p.300), "a Educação do Campo construída pelos movimentos populares de luta pela terra, organizados no movimento camponês, articula o trabalho produtivo à educação escolar tendo por base a cooperação".

A Educação do Campo pode ser definida como uma educação que parte do conhecimento empírico do educando. No entanto, não abre mão da pluralidade de conhecimento científico e sistematizado em diversas áreas. Essa nova forma de organização visa à formação global do sujeito e parte do pressuposto de que cabe à escola o papel de criar espaços de experiências variadas que oportunizem aos indivíduos a construção de sua autonomia e produção de conhecimentos sobre a realidade em que vive.

\section{Segundo Caldart (2002, p.26),}

[...] a Educação do Campo é um projeto educacional compreendido a partir dos sujeitos que têm o campo como seu espaço de vida. Nesse sentido, ela é uma educação que deve ser no e do campo - No, porque "o povo tem o direito de ser educado no lugar onde vive"; Do, pois "o povo tem direito a uma educação pensada desde o seu lugar e com a sua participação, vinculada à sua cultura e às necessidades humanas e sociais".

A Educação do Campo tem ocupado muitos espaços nos últimos anos desde os debates dos Movimentos Sociais até a conquista de políticas educacionais voltadas para o campo.

Em conformidade com o PPP do colégio, as percepções explicitadas pelos entrevistados ocorrem no sentido de que a escola à qual se referem analisa e reorganiza o currículo nos eixos temáticos e alternativas metodológicas das Diretrizes Curriculares da Educação do Campo. Além de se adequar, gradualmente, na tentativa da concretização de uma educação diferenciada, identificada com a participação dos seus povos do campo, dentro de sua realidade cultural e social (PPP, 2015).

Essa discussão precisa ultrapassar o perfil pedagógico e situar-se na vivência educacional da vida no campo. Precisa-se pensar o campo que se quer ter a partir das condições de vida de seus sujeitos e relacionar esse modo de viver com o conteúdo escolar, na perspectiva de mudança dessas relações de poder e também pensar o campo como espaço de vida e não apenas de produção.

O que caracteriza os povos do campo é o jeito peculiar de se relacionarem com a natureza, o trabalho na terra, a organização das atividades produtivas, mediante mão-de-obra dos membros da família, cultura e valores que enfatizam as relações familiares e de vizinhança, que valorizam as festas comunitárias e de celebração da colheita, o vínculo com uma rotina de trabalho que nem sempre segue o relógio mecânico. (BRASIL, 1996, p. 24).

Os sujeitos do campo têm seu jeito próprio de viver. De acordo com sua cultura, repassada e reconstruída de geração para geração, eles constroem relações sociais e seu sustento.

Nas falas dos entrevistados, nota-se uma clara preocupação em direcionar os conteúdos e objetivos de forma que os educandos possam atender às exigências tecnológicas e do mundo do trabalho, bem como a formação crítica na tomada de decisões diante das questões cotidianas de forma consciente.

Eu penso que na disciplina de ciências se a gente conseguisse trabalhar um pouco mais voltado, pois a busca de material $e$ as abordagens são trabalhosas, pois o nosso material didático não contribui em nada. Que nem agora, eu to fazendo um herbário com coleta do material que contém o herbário, quando a gente está trabalhando com os animais, sempre tento utilizar exemplos locais dando uma quebrada no que vem nos livros (E1).

Quando consigo, tento fazer ligação da minha disciplina com as coisas que os alunos convivem.. Têm algumas coisas que dá de relacionar, porque ciências e biologia estão envolvidos desde o ar que eles respira, contato com as plantas, animais, com os alimentos, com a terra, a plantação... isso auxilia no sentido de preparar um aluno que visualize ao seu redor, o que acontece com o ambiente, as modificações dele... prepara para ser pesquisador, de sempre querer buscar mais sobre o assunto (E4).

É interessante lembrar que, na pretensa mudança da educação, a ação do professor que atua nas escolas do campo é de fundamental importância. Esta ação deve ser intencional e planejada para a aplicação de metodologias diferenciadas para cada conteúdo abordado.

Nas entrevistas, foi possível a identificação de possibilidades de práticas pedagógicas utilizadas na escola, visando trabalhar a partir do conhecimento empírico dos educandos: "o herbário e o insetário são atividades que desenvolvi no projeto referente à genética, que têm relação com o cotidiano deles" (E2).

Eu gosto de fazer atividades diferenciadas, gosto de trabalhar com jogos, caça-palavras, trabalho com leitura e interpretação dentro do meu conteúdo, herbário... lá na parte dos alimentos eu gosto de fazer a prática: hoje vamos fazer a alimentação saudável e amanhã a não saudável, levamos os lanches, tudo dentro do grupo de alimentos, fazendo a comparação dos lanches, quando vai trabalhar frequência cardíaca sempre estar levando os alunos pra verificar a pressão arterial... Na parte de reprodução humana eu gosto de fazer caixinha com perguntas... Trago muitos vídeos, muitas imagens, principalmente na questão de doenças no sentido de alertar, algumas práticas simples quando possivel, lamínas prontas que leva para os alunos observar.. Trabalho também com atividades de modelagem: modelagem do sistema solar, modelagem da célula, dos sistemas respiratórios (E1).

Fiz a planificação dos sólidos geométricos, trouxe o molde, eles recortaram e montaram... Fiz a atividade pra Equipe Multidisciplinar pra eles montarem o 
artesanato indígena que dá pra relacionar com a geometria plana e espacial... Trouxe tampinha da garrafa, copinhos, xícaras e outras matérias em formato circular pra fazer o cálculo da circunferência, diâmetro e perímetro (E5).

Conforme relata a diretora, a caracterização de Educação do Campo está vinculada ao PPP da escola, pois, segundo ela: "colocamos esse diferencial no PPP da escola, então pra ter essa adequação, que sempre que possível que faça essa alteração na forma de ensinar os conteúdos aos alunos" (D).

No que se refere às práticas pedagógicas, afirma que quando se reconhece o saber utilizado no cotidiano, a disciplina terá mais significado no ambiente escolar. Sob esse ponto de vista, Vergnaud (2003, p.33) afirma que

[...] é preciso considerar de qualquer maneira que os conceitos cotidianos germinam para cima, enquanto os conceitos escolares germinam em direção ao real, ao concreto. Sempre é preciso estabelecer na escola a relação entre os conceitos escolares e os conceitos cotidianos.

No entanto, o educador, muitas vezes, não consegue fazer a relação entre o científico e o empírico. Assim, o educando se depara com a imposição de um conteúdo formal obrigatório que, na maioria das vezes, tem pouca ou nenhuma relação com seu cotidiano. Deste modo, o conhecimento que ele trazia é desperdiçado no processo de aprendizagem escolar. Nesse caso, se nega ao educando a oportunidade de ter um conhecimento que valorize sua comunidade e sua história.

O educador pode estabelecer relações com colegas de outras disciplinas de forma interdisciplinar, para analisar o desenvolvimento da aula a partir de conteúdos e materiais que possam ser relacionados à realidade dos educandos.

\begin{abstract}
[...] no meu PDE eu fiz uma atividade voltada para a Educação do Campo... voltado para os alunos que vivem aqui, e é uma dificuldade enorme em encontrar material, pois o meu projeto foi sobre animais peçonhentos e o uso do lúdico, envolvendo as disciplinas de Arte e Língua Portuguesa (E1).
\end{abstract}

Durante as entrevistas, o tema sobre a distância da realidade foi abordado como uma insistente característica das propostas dos livros didáticos: "ele é construído para o país inteiro e não abrange a realidade de todos os Estados quem dirá de um município ou de uma comunidade" (D), "Os conceitos não são bem definidos e claros, são extensos, o aluno não gosta, as imagens e os exemplos são voltados pra coisas distantes da nossa realidade" (E3). Além disso, "[...] porque ele não faz muita conexão, é bem vago, utilizo mais pra eles visualizar alguma coisa, a maioria das atividades eu trago pronta" (E2).

Uma educadora relata que, muitas vezes, no material didático, os conceitos não são bem definidos e claros, seguidos de definições muito extensas: " $O$ conteúdo é muito complexo, aí trago uma coisa mais resumida até porque duas aulas por semana em cada turma é pouco então. Além disso, as atividades são muito extensas, quase não tem atividade prática" (E5). Outrossim,

[...] as imagens e os exemplos são voltados pra coisas distantes da nossa realidade e na parte de Astronomia que é um dos conteúdos estruturantes de
Ciências, somente o livro do $6^{\circ}$ ano que contempla... tem um fragmento do sétimo e no oitavo onde a gente tem que trabalhar todos os anos. Outra coisa, nos sistemas biológicos a gente tem que estar trabalhando todo o ano e ele vem na composição do livro didático vem num modelo nacional, esquecendo que a gente tem as Diretrizes do nosso Estado, que tratam dos conteúdos estruturantes nos quatro anos... então, essa unificação de conteúdos em um único livro, faz com que você tenha que estar procurando do ano seguinte ou do ano anterior e sem contar que tem conteudos estruturantes que a gente tem que trabalhar e o livro didático não aborda (E1).

\section{Conforme menciona a coordenadora pedagógica:}

\begin{abstract}
[...] vem um padrão de livro lá de Brasília e é este que entregamos aos alunos todo ano. Lógico que também é válido para curiosidades, mas o governo deveria pensar em fazer um livro que ao menos atendesse as demandas da região $\operatorname{Sul}(P)$.
\end{abstract}

A inter-relação entre o saber popular e o saber sistematizado proporciona aos educandos compreender de modo mais aprofundado sua cultura, ou seja, ao transitar entre os saberes populares e acadêmicos, é possível despertar nos educandos maior interesse nos estudos, pois o aprendizado na escola permite a esses alunos melhor compreensão de muitas de suas atividades diárias.

A escola é o local para a ampliação de conhecimentos. Nesse sentido, a identidade e o cotidiano dos sujeitos do campo devem ser tomados como premissa para o trabalho pedagógico. É também a referência para selecionar os conteúdos escolares e os materiais didáticos a serem trabalhados em sala.

Dessa forma, a educação é um importante elo entre a vida do educando e a sua maneira de entender e relacionar-se com a sociedade. De acordo com Libâneo (2001, p.10),

[...] a escola tem, pois, o compromisso de reduzir a distância entre a ciência cada vez mais complexa e a cultura de base produzida no cotidiano, e é provida pela escolarização. Junto a isso tem, também, o compromisso de ajudar os alunos a tornarem-se sujeitos pensantes, capazes de construir elementos e categorias de compreensão e apropriação crítica da realidade.

Da exigência citada pelo autor supracitado, o professor, como responsável pela organização e metodologia da aula, tem o papel principal de levantar questões que proporcionem situações que favoreçam a conexão das disciplinas à realidade dos educandos, estimulando-lhes a discussão e a partilha de ideias.

No entanto, percebe-se que nem sempre é possível desenvolver os objetivos planejados. O uso de termos científicos, sem relação com o cotidiano, dificulta a compreensão por parte dos educandos. Além disso, a organização dos espaços e tempos escolares não permite a realização de trabalhos práticos e de recursos tecnológicos.

As crianças e jovens das diferentes regiões do campo do município específicos em estudo apresentam modos de vida que acompanham o trabalho de seus pais, com as plantações e no cuidado com os animais. Desta maneira, o professor precisa observar a realidade de seus estudantes, porque essa informação irá auxiliar o trabalho de base para planejar tanto o ensino como a aprendizagem dos conteúdos elencados na Proposta Curricular de cada disciplina. Essa proposta almeja ser 
construída a partir do perfil do aluno, o qual, em sua maioria, é filho de pequenos agricultores, criadores de gado de corte e de leite e trabalhadores braçais.

No entanto, ainda assim, a maioria dos alunos, ao concluir o Ensino Médio, vai para as cidades em busca de emprego. E, conforme relata a diretora,

\begin{abstract}
[...] devemos encontrar uma forma de fazer uma Educação do Campo diferenciada, que é realmente buscar essa realidade dos nossos alunos... tanto que a gente está acreditando na formação dos professores que estão tentando, e estamos com esperança que esses alunos que estão saindo pra estudar comecem a voltar e atuar, a contribuir e a ajudar na escola... a gente tem alguns estágios da UFFS que se comprometeram a fazer essa mediação maior pra que aos poucos vá se efetivando essa educação que almejamos (D).
\end{abstract}

A Educação do Campo assume sua particularidade, que é o vínculo com sujeitos sociais concretos, mas sem se desligar da universalidade: antes de tudo, ela é educação, formação de seres humanos. Conforme relata a coordenadora pedagógica, "eu vejo que é um trabalho coletivo, mais trabalho pra melhorar, me comprometo sempre com as particularidades da escola" (P).

Nesse sentido, o planejamento intenta direcionar os conteúdos das disciplinas de forma a valorizar os alunos residentes na zona rural, visando e pleiteando parcerias com os órgãos da agricultura, como a Empresa de Assistência Técnica e Extensão Rural (EMATER), a Secretaria da Agricultura do município (SEAB), a Central de Comercialização, as Cooperativas, o Sindicato Rural, dentre outros, assim como Universidades da região. Dessa forma, a comunidade escolar acolhe e também organiza palestras proferidas por especialistas no assunto em parcerias com órgãos do Estado (PPP, 2015). Nesse aspecto,

\begin{abstract}
[...] o que a gente tenta buscar é parcerias com as Universidades que ofereçam as palestras, que façam a divulgação dos cursos que são oferecidos, para tentar incentivar e tentar trazer um pouco dessa realidade da Educação do Campo para as escolas do campo... A UFFS de Laranjeiras ela busca trabalhar com essas questões ligadas mais as especificidades do campo e por isso sempre buscamos essa parceria, até tempos alunos que estudam lá e estão fazendo estágios aqui, bem como na Semana Cultural nós trouxemos alunos de lá pra vim conversar com os alunos e propor atividades de recreação a eles... A UNICENTRO que formou a turma da Ledoc que teve professores além de você trabalhando aqui conosco... As vezes a gente encontra alguma dificuldade nesse contato também, porque nem sempre eles estão dispostos a vir, pela distância ou alguma outra coisa. As vezes programamos umas três palestras e conseguimos realizar apenas uma (D).
\end{abstract}

Assim, a Educação do Campo faz o diálogo com a teoria pedagógica desde a realidade particular dos camponeses ou, mais amplamente, da classe trabalhadora do campo e de suas lutas.

\subsection{Perspectivas de manutenção de jovens no campo}

Quando os estudantes participantes da pesquisa foram questionados se pretendiam cursar o Ensino Superior, 17 alunos (26\%) marcaram a opção que não pretendem continuar os estudos. Os motivos pelos quais não querem estudar são diversos e foram apontados: "devido à minha condição financeira" (A58), "quero arrumar um emprego antes" (A7), "pretendo ajudar meus pais" (A25), "não tenho interesse" (A24), "é chato estudar e dá mais lucro ser fazendeiro" (A59), "não gosto de estudar" (A42). Destes 17 alunos, 6 não justificaram os motivos que os levam a não querer continuar os estudos.

Os demais alunos (74\%) pretendem continuar estudando. A maioria das justificativas concerne a melhorias de vida e de condição financeira: "para conquistar o que eu quero" (A27), "por melhores condições de vida" (A62), "para ter um futuro melhor e uma boa condiçẫo de vida" (A47), "para ter uma formação superior e para conseguir um emprego que e goste" (A63), "para ter um meio de sobreviver e ter algo profissional" (A9), "[...] pretendo me formar em alguma especialidade" (A4), "eu quero aprender coisas novas e ter mais conhecimento" (A21).

Para a coordenadora pedagógica, ver que grande parte dos alunos da escola tem o interesse em continuar os estudos é uma forma gratificante e de incentivo para prosseguir trabalhando como coordenadora pedagógica. Segundo ela,

\begin{abstract}
[...] quando a gente vê nossos alunos tendo sucesso ai fora... vemos tantos alunos que viraram professores, ou que estão fazendo uma faculdade em universidades públicas, curso técnico, entrando no mercado de trabalho... Poderiam ser todos mas a gente sabe que não vão ser todos...eu vejo a educação avança quando alunos aqui dessas comunidades estão se dando bem (P).
\end{abstract}

A partir dos alunos que pretendem prosseguir nos estudos, foi questionado se a pretensa profissão teria alguma vinculação com o campo onde residem. Assim, 31 estudantes $(48 \%)$ responderam que planejam depois de formados manter conexão com o campo. As formações almejadas estão ligadas a ser Técnico em Agropecuária, à Agronomia, Veterinária, Medicina, a ser Professor de Educação Básica, Piscicultura, Enfermeira, Psicologia e à Administração. As explicações de como manterão essa vinculação podem ser compreendidas nas seguintes falas: "posso trabalhar em escolas do campo" (A44), "ser médico no campo é indispensável" (A61), "[...] é ligado com agricultura" (A4), "posso ajudar meu pai na propriedade" (A9), "[...] posso melhorar a situação financeira da propriedade" (A51), "gosto de cuidar dos animais" (A2), "eu nasci e me criei aqui, por isso pretendo aqui continuar" (A52).

Atualmente, a Educação do Campo vem conquistando seu espaço, mas há muito em que avançar. Um exemplo de mudança refere-se às lutas para debater as relações históricas e estruturais. Isso será possível somente se os interessados, no caso a comunidade escolar (professores, alunos, funcionários, pais), se responsabilizarem por essa construção e por esse diferencial nas escolas, na luta pela qualidade na educação ofertada e na melhoria das estruturas das escolas do campo, conferindo-lhes mais qualidade e acesso. Ainda, ações que priorizem a educação da sociedade e que contribuam para o processo de crescimento e mudanças positivas desta sociedade e, além disso, que contribuam para permanência no campo, na vida dos alunos e da comunidade pelo processo emancipatório de seus cidadãos, cidadãos do campo. 


\section{Considerações finais}

As conquistas alcançadas no decorrer dos últimos anos referentes à Educação do Campo, como leis específicas para os sujeitos que vivem e trabalham no campo, expressam um passo importante na garantia e acesso de condições educacionais mais específicas para esses sujeitos. Porém, ainda há muito que se caminhar no que diz respeito à escola e às disciplinas, vinculadas às especificidades no campo.

A análise dos dados coletados pela pesquisa permitiu identificar que avanços relacionados à Educação do Campo chegaram timidamente à escola. Nas entrevistas, entende-se que já se tem uma metodologia que tenta se adequar a essas especificidades, mas a realização do ensino de forma articulada ao modo de vida e à cultura camponesa ainda é limitada.

As análises efetuadas dos questionários mostraram que os aluno têm um sentimento de pertença ao campo, muitos dos quais pretendem continuar seus estudos, mas sem perder o vínculo com o campo. No que se refere ao ensino contextualizado, relatam que já tiveram experiências de atividades sugeridas pelo professor, as quais estavam vinculadas à sua realidade, por isso, conseguiram relacioná-las com alguma característica do lugar onde moram. Muitas vezes, conexões simples, mas que auxiliam na contextualização do conteúdo científico trabalhado na escola quanto às semelhanças de sua cultura camponesa.

\section{Notas:}

1 “A Pedagogia do Oprimido se insere no movimento de educação e cultura popular que se dá no final dos anos 1950 e se prolonga até os anos 1960. [...] E uma concepcão e prática pedagógica construídas e reconstruídas nas experiências sociais e históricas de opressão e nas resistências dos oprimidos, dos movimentos sociais pela libertação de tantas formas persistentes de opressão." (ARROYO, 2012, p. 556).

2 "Soberania alimentar é o conjunto de políticas públicas e sociais que deve ser adotado por todas as nações, em seus povoados, municípios, regiões e países, a fim de se garantir que sejam produzidos os alimentos necessários para a sobrevivência da população de cada local." (STEDILE; CARVALHO, 2012, p 717).

\section{Referências}

ARROYO, M.G.; CALDART, R.S.; MOLINA, M.C. (Org.). Por uma Educação do Campo. 4. ed. Petrópolis: Vozes, 2009.

ARROYO, M.A. Pedagogia do Oprimido. In: CALDART, R.S.; PEREIRA, I.B.; ALENTEJANO, P.; FRIGOTTO, G. (Org.). Dicionário da Educação do Campo. Rio de Janeiro: Escola Politécnica de Saúde Joaquim Venâncio, 2012.

BARDIN, L. Análise de Conteúdo. Trad. Luís Antero Reto e Augusto Pinheiro. Lisboa: Edições 70, 1977.

BRASIL. Constituição (1988). Constituição da República Federativa do Brasil. Brasília, DF: Senado Federal, 2010.
CALAZANS, M.J. Questões e contradições da Educação Rural no Brasil. In: WERTHEIN, J. (Org.). Educação Rural no Terceiro Mundo: experiências e novas alternativas. Rio de Janeiro: Paz e Terra, 1981. p 161-198.

CALDART, R.S. Por uma Educação do Campo: traços de uma identidade em construção. Caderno 4. Brasília: Articulação Nacional "Por uma Educação do Campo", 2002.

CALDART, R.S. Educação do Campo. In: CALDART, R.S.; PEREIRA, I.B.; ALENTEJANO, P.; FRIGOTTO, G. (Org.). Dicionário da Educação do Campo. Rio de Janeiro: Escola Politécnica de Saúde Joaquim Venâncio, 2012.

PPP. Projeto Político-Pedagógico. COLÉGIO Estadual do Campo de Rio da Prata. Projeto Político Pedagógico: Ensino Fundamental e Médio. Nova Laranjeiras, 2015.

FLICK, U. Introdução à pesquisa qualitativa. Tradução: Joice Elias Costa. 3. ed. Porto Alegre: Artmed, 2009. 405 p.

KOLLING, E.J.; CERIOLI, P.R.; CALDART, R.S. Educação do Campo: identidade e políticas públicas. Brasília: Articulação Nacional por uma Educação do Campo, 2002.

KOLLING, E.J.; NERY, I.; MOLINA, M.C. Por uma educação básica do campo (memória). Brasília: Articulação Nacional por uma Educação do Campo, 1999.

LEITE, S.C. Escola rural: urbanização e políticas educacionais. São Paulo: Cortez, 1999.

LIBÂNEO, J.C. Democratização da escola pública. 16. ed. São Paulo: Loyola, 2001.

MINAYO, M.C.S. O Desafio do Conhecimento: Pesquisa Qualitativa em Saúde. 10. ed. São Paulo: HUCITEC, 2007.

PARANÁ. Secretaria de Estado da Educação. Diretrizes Curriculares da Educação do Campo. Curitiba, 2006.

PARANÁ. Secretaria de Estado da Educação. Superintendência da Educação. In: Caderno Temático da Educação do Campo, 2., 2009. Coordenação da Educação do Campo. Curitiba, 2009.

RIBEIRO, M. Educação Rural. In: CALDART, R.S.; PEREIRA, I.B.; ALENTEJANO, P.; FRIGOTTO, G. (Org.). Dicionário da Educação do Campo. Rio de Janeiro: Escola Politécnica de Saúde Joaquim Venâncio, 2012.

STEDILE, J.P.; CARVALHO, H.M. Soberania Alimentar. In: CALDART, R.S.; PEREIRA, I.B.; ALENTEJANO, P.; FRIGOTTO, G. (Org.). Dicionário da Educação do Campo. Rio de Janeiro: Escola Politécnica de Saúde Joaquim Venâncio, 2012.

TRIVIÑOS, A.N.S. Introdução à pesquisa em ciências sociais: a pesquisa qualitativa em educação. São Paulo: Atlas, 1987.

VERGNAUD, G. A gênese dos campos conceituais. In: GROSSI, E.P. Por que ainda há quem não aprende: $\mathrm{A}$ teoria. Petrópolis: Vozes, 2003.

BRASIL. Lei de Diretrizes e Bases. Lei n 9394/96.

Brasília, DF: Senado Federal, 1996. 